\title{
Single and Repeated Intrapleural Ropivacaine Administration: A Plasma Concentration and Pharmacodynamics Study
}

This article was published in the following Dove Press journal:

Journal of Pain Research

\author{
Yuanqing Chen' \\ Yaoyao Cai' \\ Yingchao $\mathrm{Ye}^{\prime}$ \\ Yun $\mathrm{Xia}^{2}$ \\ Thomas J Papadimos ${ }^{2}$ \\ Le Liu' \\ Xuzhong $\mathrm{Xu}^{3}$ \\ Quanguang Wang' \\ Kejian Shi ${ }^{1}$ \\ Yiquan $\mathrm{Wu}^{\prime}$ \\ 'Department of Anesthesiology, The \\ First Affiliated Hospital of Wenzhou \\ Medical University, Zhejiang, People's \\ Republic of China; ${ }^{2}$ Department of \\ Anesthesiology, The Ohio State \\ University Wexner Medical Center, \\ Columbus, OH, USA; ${ }^{3}$ Private \\ Anesthesiology Consultant, Wenzhou, \\ People's Republic of China
}

Background: Intrapleural analgesia has been increasingly recommended for postoperative analgesia after thoracic surgery. However, the analgesic effect provided by a single intrapleural administration is time limited. This study reports the efficacy and safety of repeated intrapleural $0.75 \%$ ropivacaine administration after thoracoscopic surgery.

Methods: Twenty patients were randomly divided into two groups: a single administration group receiving a single intrapleural injection of $0.75 \%$ ropivacaine $15 \mathrm{~mL}$ (single administration group, SA group), and a repeated administration group with an intrapleural injection of $0.75 \%$ ropivacaine $15 \mathrm{~mL}$ every $4 \mathrm{~h}$ for 4 doses (repeated administration group, RA group). The primary outcomes of this study were the peak plasma concentration of ropivacaine and $24 \mathrm{~h}$ morphine consumption. The secondary outcomes were pain score, patient satisfaction, extubation time, hospital length of stay, and adverse reactions.

Results: In SA group, the highest plasma concentration after intrapleural administration of $0.75 \%$ ropivacaine $15 \mathrm{~mL}$ was $1345 \pm 364 \mu \mathrm{g} / \mathrm{L}$. The highest plasma concentration in RA group after the fourth administration was $1864 \pm 492 \mu \mathrm{g} / \mathrm{L}$. The $24 \mathrm{~h}$ morphine consumption in RA group was significantly less than that in SA group ( $9.0 \pm 5.66$ vs $15.9 \pm 3.48 \mathrm{mg}, P=0.004)$. The NRS scores at rest and while coughing of patients in RA group were significantly lower than those in SA group at 5, 9, 13, 17 and 24h after operation. The patients in RA group had higher satisfaction than those in SA group. There was no significant difference in postoperative adverse events, drainage tube placement days and hospital length of stay between the two groups.

Conclusion: Repeated intrapleural administration with $0.75 \%$ ropivacaine, $15 \mathrm{~mL}$ every $4 \mathrm{~h}$ for 4 doses after video-assisted thoracoscopic lobectomies, can provide a more durable and more effective analgesic effect than single intrapleural administration. Repeated intrapleural administration of ropivacaine is an effective postoperative method of analgesia resulting in higher patient satisfaction. Moreover, it was also able to keep the plasma concentration of ropivacaine within a possible safe range.

Clinical Trial Registration Number: ChiCTR-IOR-17010560.

Keywords: intrapleural analgesia, ropivacaine, dosage

\section{Introduction}

Patients undergoing video-assisted thoracoscopic surgery (VATS) suffer moderate to severe pain, and incomplete analgesia that may affect the postoperative recovery of pulmonary function. The acute pain after VATS is primarily (1) incisional, and (2) due to thoracic drainage tube abutment against the parietal pleura. ${ }^{1-5}$ Therefore, intrapleural analgesia has been increasingly recommended for postoperative analgesia after thoracic surgery due to its simplicity, convenience and safety.

Yiquan $\mathrm{Wu}$

Department of Anesthesiology, The First Affiliated Hospital of Wenzhou Medical

University, South Baixiang Town,

Wenzhou City, Zhejiang Province,

325000, People's Republic of China

Tel +86-138677I5375

Email wuyiquanspring@126.com 
Clinical studies have confirmed the safety and effectiveness of intrapleural analgesia after thoracic surgery. ${ }^{5-8}$ Chen et $\mathrm{al}^{6}$ demonstrated the effectiveness of intrapleural analgesia for postoperative pain relief after thoracoscopic surgery. In that study intrapleural analgesia with $0.75 \%$ ropivacaine $(15 \mathrm{~mL}$ or $20 \mathrm{~mL})$ effectively relieved pain due to coughing after thoracoscopic surgery. However, the duration of analgesia provided by single intrapleural administration is time limited. Tetik et $\mathrm{al}^{7}$ confirmed that an injection of $0.25 \%$ bupivacaine $40 \mathrm{~mL}$ via the thoracic drainage tube provided $5 \mathrm{~h}$ of analgesia after thoracic surgery, therein making the recommendation to repeat the dose every $6 \mathrm{~h}$ via the thoracic drainage tube. Chen et $\mathrm{al}^{6}$ reported that the median duration of intrapleural analgesia after the administration of $0.75 \%$ ropivacaine, $15 \mathrm{~mL}$ and $20 \mathrm{~mL}$, was 320 minutes. The concentration, dosage and the method of administration of local anesthetics affect the duration of intrapleural analgesia. Therefore, the question arises as to the effectiveness of repeated intrapleural boluses in the provision of better and longer postoperative analgesia. Additionally, the question of the safety of repeated boluses and adverse consequences needs to be addressed. Currently, no such studies have been reported.

Therefore, we prospectively enrolled patients randomly that were undergoing thoracoscopic lobectomy to study the efficacy and safety of repeated intrapleural ropivacaine administration. We hypothesized that, compared with single administration of intrapleural analgesia, repeated administration can provide a more effective analgesic effect, longer duration of analgesia, and a safe range of plasma ropivacaine concentration for patients after VATS. The main outcomes measured in this study were peak ropivacaine plasma concentration and the $24 \mathrm{~h}$ morphine consumption after surgery. The secondary outcomes measured were Numerical Rating Scale (NRS), patient satisfaction, thoracic drainage tube placement days, hospital length of stay, and adverse reactions.

\section{Materials and Methods}

\section{Participants}

Following approval by the Ethics Committee of the First Affiliated Hospital of Wenzhou Medical University (Clinical Research Ethics Number 2016-217), clinical registration number ChiCTR-IOR-17010560, 20 patients scheduled for videoassisted thoracoscopic lobectomy, age $\geq 18$ years, BMI $15-30 \mathrm{~kg} / \mathrm{m}^{2}$, ASA I-III were enrolled, 10 patients in each group, and a written informed consent was obtained from all subjects participating in the trial. Exclusion criteria were history of allergy to local anesthetics or general anesthetics, abnormalities in platelet or coagulation function, serious hepatic or renal insufficiency, cardiopulmonary insufficiency, history of acute and chronic pain; recent use of opioids or local anesthetics, history of alcohol or opioid dependence, an inability to communicate with the patient, severe mental or neurological diseases. Preoperatively, patients were instructed how to use the patient-controlled analgesia (PCA) device and express their level of pain using the NRS $(0=$ no pain, $10=$ the worst pain than you can imagine).

\section{Study Design}

Patients received no preoperative medications, fasted for $8 \mathrm{~h}$, and were deprived of water $2 \mathrm{~h}$ before surgery. Patients were monitored by electrocardiography (ECG), invasive arterial blood pressure (IBP) and pulse oximetry (SpO2). All patients had peripheral venous access established in an upper limb.

General anesthesia was induced by intravenous infusion of sufentanil $(0.3 \mu \mathrm{g} / \mathrm{kg})$, propofol $(2 \mathrm{mg} / \mathrm{kg})$ and rocuronium $(0.6 \mathrm{mg} / \mathrm{kg})$ for facilitation of intubation using a selective endobronchial tube with positioning guided by fiberoptic bronchoscopy. Anesthesia was maintained with intravenous propofol, remifentanil, and sevoflurane (MAC 0.6). The bispectral index (BIS) was maintained between 40 and 60 . After the procedure was completed, a closed thoracic drainage tube (F26, Suzhou Instrument Standard 20152660866, Suzhou McLean Medical Devices Co., Ltd., China) and a 3-hole epidural catheter (National Instrument Standard 20173664119, Zhejiang Haisheng Medical Instrument Co., Ltd., China) were inserted into the pleural cavity under direct vision by surgeon. The epidural catheter (used for intrapleural analgesia) was placed into one of the side holes of the thoracic drainage tube, passing through the head end of the closed thoracic drainage tube. The head of the epidural catheter was placed $2 \mathrm{~cm}$ beyond the drainage tube, which was fixed near the head end of the drainage tube (Figure 1). When the patient was fully awake and able to breathe spontaneously, the endobronchial tube was removed. After being sent to the post-anesthesia care unit, all patients were instructed to lie flat after an intrapleural injection of $0.75 \%$ ropivacaine $15 \mathrm{~mL}$. The drainage tube was then clamped for 15 min before reopening. Patients in RA group were given intrapleural injection with $0.75 \%$ ropivacaine $15 \mathrm{~mL}$ every $4 \mathrm{~h}$ for 4 doses.

Each patient received intravenous patient-controlled analgesia (PCA) device for postoperative pain control (ZZB-1, Apon Medical Technology Co., Ltd. Jiangsu, China), which contained $100 \mathrm{mg}$ morphine in $200 \mathrm{~mL}$ saline. 

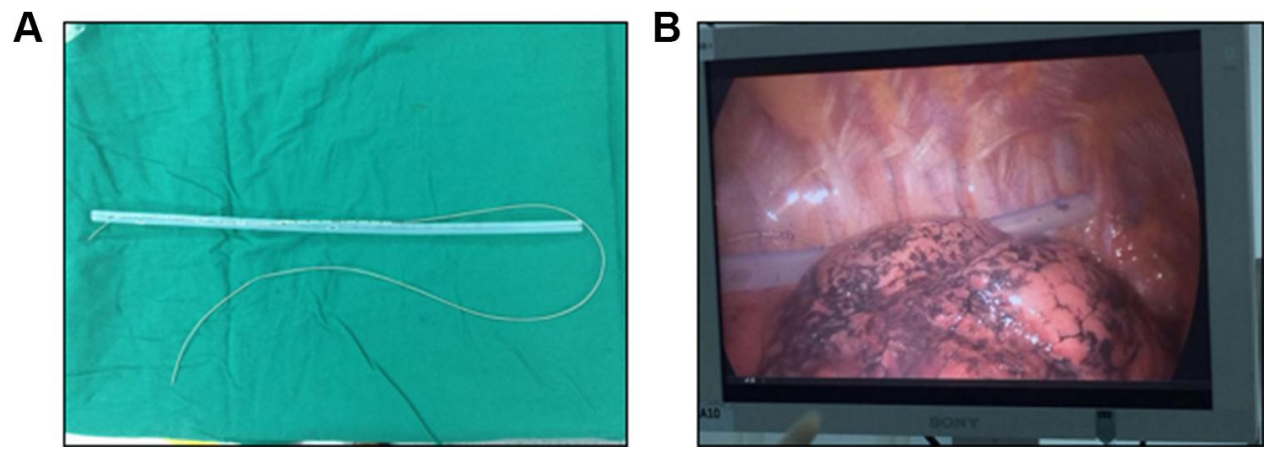

Figure I The location of the epidural catheter and the drainage tube. (A) Schematic diagram of the placement of a closed chest drainage tube and a three-port epidural catheter. (B) The closed pleural drainage tube and three-hole epidural catheter placed in the thoracic cavity.

The PCA device settings were: no baseline administration, self-controlled analgesia lockout time of 5 min (allowing a self-administered dose of $2 \mathrm{~mL}$ ), for $48 \mathrm{~h}$ postoperatively. Patients with an NRS score $\geq 4$ were allowed PCA adjustments. At $48 \mathrm{hr}$ postoperatively, all patients were given flurbiprofen (2E108P, Beijing Tide Pharmaceutical Co., Ltd., China) $100 \mathrm{mg}$ twice a day for analgesia. The patients' satisfaction with the analgesic technique was evaluated by a 5-point digital scale: 1 = very dissatisfied; $2=$ unsatisfactory; 3 = satisfied; $4=$ somewhat satisfactory; $5=$ very satisfied. $^{9}$

\section{Groups}

SA group: The concentration of ropivacaine in arterial blood was measured at 5, 10, 15, 20 and 30 min after intrapleural injection of $0.75 \%$ ropivacaine $15 \mathrm{~mL}$. The NRS scores at rest and while coughing were recorded before intrapleural administration ( $0 \mathrm{~min}$ ) and at $10 \mathrm{~min}, 20 \mathrm{~min}, 30 \mathrm{~min}, 1 \mathrm{~h}, 5 \mathrm{~h}, 9 \mathrm{~h}, 13 \mathrm{~h}$, $17 \mathrm{~h}$ and $24 \mathrm{~h}$ after administration. The patients' total morphine consumption at $24 \mathrm{~h}$ after surgery was recorded, and the adverse events within the first 24 hours postoperatively, such as hypotension, respiratory depression, nausea and vomiting, and local anesthetic toxicity (arrhythmia, blood pressure, dizziness, tinnitus, paresthesias, perioral numbness), as well as patient satisfaction, drainage tube placement days and hospital length of stay.

RA group: The concentration of ropivacaine in arterial blood was measured before intrapleural administration and at 5, 10, 15, 20 and 30 min after the first and the fourth intrapleural administration. The NRS scores of the patients at rest and while coughing were recorded initially and at $10 \mathrm{~min}, 20$ $\min , 30 \mathrm{~min}, 1 \mathrm{~h}, 5 \mathrm{~h}, 9 \mathrm{~h}, 13 \mathrm{~h}, 17 \mathrm{~h}$ and $24 \mathrm{~h}$ after the first intrapleural administration of $0.75 \%$ ropivacaine. The patients' total morphine consumption with in $24 \mathrm{~h}$ was also recorded. Each patient was observed for at least $30 \mathrm{~min}$ after each administration and adverse events such as hypotension, respiratory depression, nausea and vomiting, and local anesthetic toxicity within $24 \mathrm{~h}$ after surgery were recorded, as were patient satisfaction, drainage tube placement days and hospital length of stay.

\section{Ropivacaine Concentration}

A radial artery blood sample of $2 \mathrm{~mL}$ was collected and underwent centrifugation at $2500 \mathrm{rpm}$ for $15 \mathrm{~min}$; the supernatant was stored in the refrigerator at $-80^{\circ} \mathrm{C}$. The concentration of ropivacaine in arterial blood samples was determined by HPLC-MS/MS.

UPLC-MS/MS: Plasma samples underwent centrifugation at $13000 \mathrm{rpm}$ for $10 \mathrm{~min}$; a $100 \mathrm{uL}$ supernatant was moved in a $1.5 \mathrm{~mL}$ centrifuge tube, to which $30 \mu \mathrm{L}$ bupivacaine $50 \mathrm{ng} / \mathrm{mL}$ as internal standard was added, along with $200 \mu \mathrm{L}$ acetonitrile. The mixture was vortexed for $2 \mathrm{~min}$, and then underwent centrifugation at $13000 \mathrm{rpm}$ for $10 \mathrm{~min}$. The supernatant was collected and diluted 1:1 with ultrapure water for UPLC-MS/MS analysis. Chromatography conditions were as follows: Chromatography column Waters ACQUITY BEH C18 column (2.1 mm x $50 \mathrm{~mm}, 1.7 \mathrm{um}$ ); column temperature: $40^{\circ} \mathrm{C}$; injection volume: $2 \mu \mathrm{L}$; mobile phase: $0.1 \%$ formic acid, acetonitrile. Mass spectrometry conditions were as follows: multiple reaction monitoring (MRM) mode; desolvation gas flow: $\mathrm{N}_{2}$, flow rate $1000 \mathrm{~L} / \mathrm{h}$; temperature: $500^{\circ} \mathrm{C}$; ion source temperature: $150^{\circ} \mathrm{C}$.

The UPLC-MS/MS method used in this experiment has been verified by methodology such as recovery rate, matrix effect, precision and stability.

\section{Statistical Analysis}

The power analysis was based on results of our preliminary study using the Power Sample Size (PASS11.0) software program (NCSS Inc, Kaysville, UT). The preliminary 
experiment included 5 patients in each group and the main outcome studied was $24 \mathrm{~h}$ morphine consumption. The $24 \mathrm{~h}$ morphine consumption in SA group and RA group was $10.0 \pm 3.2 \mathrm{mg}$ and $4.8 \pm 2.3 \mathrm{mg}$, respectively. Using an $\alpha=0.05$ and $\beta=0.1,8$ people were needed in each group. Considering potential losses and errors, it was determined that there should be 10 patients in each group for the trial.

All data were analyzed using SPSS19.0 software. The measurement data of normal distribution were expressed as Mean $\pm \mathrm{SD}$, otherwise the median (quartile) was used, and the classification data was expressed as (\%). The general data, morphine consumption, drainage tube placement days and the hospital length of stay of the two groups were compared using an independent sample $t$-test. The Rank Sum Test was used to compare ASA classification, gender, patient satisfaction and NRS score. Statistical significance was considered as $P<0.05$.

\section{Results}

There was no significant difference between the two groups' demographic data including age, gender, height, weight, BMI, ASA classification, and surgery time (Table 1).

In SA group, the highest plasma ropivacaine concentration after intrapleural administration of $0.75 \%$ ropivacaine $15 \mathrm{~mL}$ was $1345 \pm 364 \mu \mathrm{g} / \mathrm{L}$. The highest plasma ropivacaine concentration in RA group after the fourth administration was $1864 \pm 492 \mu \mathrm{g} / \mathrm{L}$. In SA group, the plasma ropivacaine concentration at 5, 10, 15, and 20 min after the administration was significantly lower than that at the corresponding time point after the fourth administration in RA group.

The concentration of ropivacaine in arterial blood at 5, 10, $15,20,30$ min after administration in SA group and the concentration of ropivacaine at 5, 10, 15, 20, 30 min after the first and fourth administration in RA group are shown in Figure 2.

The $24 \mathrm{~h}$ morphine consumption of patients in RA group was significantly less than that in SA group $(P=0.004)$ (Table 2).

The NRS scores at rest of patients in RA group were significantly lower than those in SA group at 5, 9, 13 and 17h $(P=0.04, P=0.03, P=0.045, P=0.044$, respectively). The NRS scores while coughing of patients in RA group were significantly lower than those in SA group at 5, 9, 13, 17 and 24h $(P=0.01, P<0.01, P=0.025, P=0.024, P=0.035$, respectively) (Figure 3).

Patient satisfaction in RA group was significantly better than that in SA group ( $P=0.048$, Table 2$)$. There was no statistical difference in thoracic drainage tube placement days and hospital length of stay between the
Table I Baseline Values of the 2 Groups $(n=10)$

\begin{tabular}{|l|c|c|c|}
\hline & SA Group & RA Group & $P$ \\
\hline Age $(\mathrm{y})$ & $57.4 \pm 3.337$ & $53.4 \pm 3.35 \mathrm{I}$ & $0.4 \mathrm{I}$ \\
\hline Gender $(\mathrm{F} / \mathrm{M})$ & $6 / 4$ & $5 / 5$ & 0.65 \\
\hline Height $(\mathrm{cm})$ & $162.3 \pm \mathrm{I} .599$ & $162.9 \pm 1.567$ & 0.79 \\
\hline Weight $(\mathrm{kg})$ & $59.5 \pm 3.879$ & $59.5 \pm 2.525$ & 0.99 \\
\hline BMI $\left(\mathrm{kg} / \mathrm{m}^{2}\right)$ & $22.49 \pm \mathrm{I} .256$ & $22.36 \pm 0.688$ & 0.93 \\
\hline ASA grade $(\mathrm{I} / \mathrm{lI} / \mathrm{III})$ & $4 / 4 / 2$ & $3 / 6 / \mathrm{I}$ & $0.7 \mathrm{I}$ \\
\hline Operation time $(\mathrm{h})$ & $1.336 \pm 0.1308$ & $1.531 \pm 0.2534$ & 0.5 \\
\hline
\end{tabular}

two groups (Table 2). The variation of blood pressure and heart rate in the two groups were both within $20 \%$ of the baseline values during the $24 \mathrm{~h}$ after surgery. One patient's $\mathrm{SpO}_{2}$ was lower than $95 \%$ in $\mathrm{SA}$ group; no patients' $\mathrm{SpO}_{2}$ was lower than $95 \%$ in $\mathrm{RA}$ group $(P>0.05)$. Three patients suffered nausea and vomiting and one suffered dizziness within $24 \mathrm{~h}$ after surgery in SA group; 4 patients complained nausea and vomiting and one complained dizziness within $24 \mathrm{~h}$ after surgery in RA group $(P>0.05)$.

\section{Discussion}

The results of this study demonstrated that compared with a single intrapleural administration, repeated intrapleural administration of $0.75 \%$ ropivacaine $15 \mathrm{~mL}$ every $4 \mathrm{~h}$ for 4 doses significantly reduced morphine consumption and pain scores in the first $24 \mathrm{~h}$ after thoracoscopic lobectomy, resulting

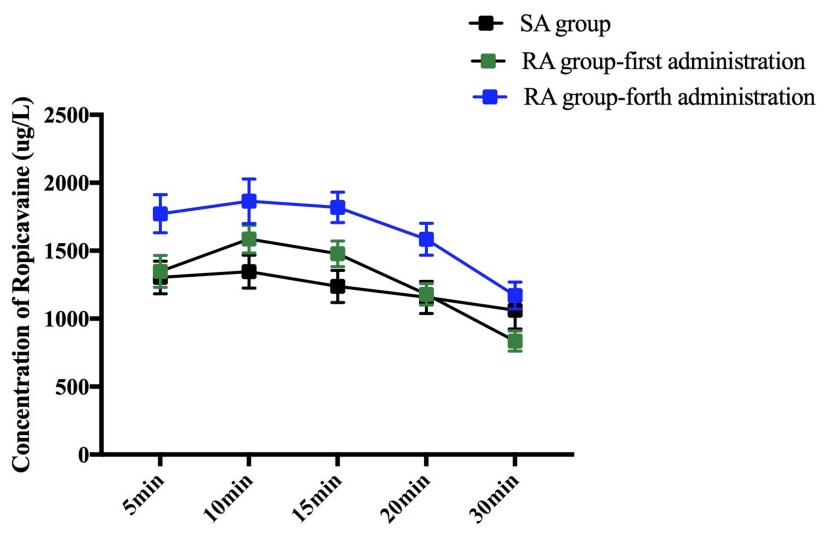

Figure 2 The plasma ropivacaine concentration of the two groups after administration. SA group: the mean concentration of ropivacaine after administration in SA group. RA group-first administration: the mean concentration of ropivacaine after first administration in RA group. RA group-fourth administration: the mean concentration of ropivacaine after the fourth administration in RA group. 
Table 2 Morphine Consumption, Patient Satisfaction, Drainage Tube Placement Days, Hospital Length of Stay $(n=10)$

\begin{tabular}{|l|c|c|c|}
\hline & SA Group & RA Group & $P$ \\
\hline $24 h$ morphine consumption & $15.9 \pm 3.48$ & $9.0 \pm 5.66$ & 0.004 \\
\hline Patient satisfaction & & & 0.048 \\
\hline 5 (Very satisfactory) & 2 & 7 & \\
\hline 4 (Somewhat satisfactory) & 6 & 2 & \\
\hline 3 (Satisfactory) & 2 & 1 & \\
\hline 2 (Unsatisfactory) & 0 & 0 & \\
\hline I (Very unsatisfactory) & 0 & 0 & \\
\hline Hospital length of stay (d) & $11.3 \pm 1.89$ & $10.8 \pm 2.62$ & 0.63 \\
\hline $\begin{array}{l}\text { Drainage tube placement } \\
\text { days (d) }\end{array}$ & $4.5(2.75,5)$ & $3.5(3,5)$ & 0.873 \\
\hline
\end{tabular}

in higher patient satisfaction while at the same time maintaining the plasma ropivacaine concentration in a safe range.

The specific mechanism of intrapleural analgesia is currently unclear. Durrani et $\mathrm{al}^{10}$ hypothesized that the mechanism of intrapleural analgesia involved anesthetic diffusion into the pleural cavity, thereby blocking multiple intercostal nerves, upper limb sympathetic nerve chains, brachial plexus nerves, visceral nerves, phrenic nerves, the celiac plexus, and other nerve plexus above and below the diaphragm to exert effective analgesia. The presence of stomata, with a diameter of 2-12 $\mu \mathrm{m}$, between the mesothelial cells of the parietal pleura have been identified as channels for anesthetic diffusion. ${ }^{11}$ It has been noted that thoracic drainage tubes can cause pleural cavity pain through body posture/movement and the inhalation/exhalation cycle of respiration after VATS. ${ }^{12}$ Intrapleural anesthetic administration can significantly reduce the pain caused by thoracic drainage tubes through the infiltration of an intrapleural local anesthetic. In this study, we used a threehole epidural catheter placed parallel to the thoracic drainage tube and injected a $15 \mathrm{~mL}$ volume of local anesthetic in a relatively short period of time (which facilitated better diffusion through a higher injection pressure). The three openings of the epidural catheter permitted the local anesthetic to be sprayed in a more even manner in the intrapleural space. In previous studies, the median time of intrapleural analgesia with $0.75 \%$ ropivacaine $15 \mathrm{~mL}$ to take effect was $6 \mathrm{~min}^{6}{ }^{6}$ Therefore, the thoracic drainage tube was clamped for $15 \mathrm{~min}$ in order to ensure the effect of ropivacaine.

The time interval between administrations in this study depended upon the effective duration of ropivacaine. The median effect time of a single administration of $0.75 \%$ ropivacaine, $15 \mathrm{~mL}$ or $20 \mathrm{~mL}$, in the pleural cavity is $320 \mathrm{~min}^{6}{ }^{6} 50 \%$ of patients had NRS score $\geq 4$ after $4 \mathrm{~h}$ post administration. ${ }^{6}$ Similarly, Ishikawa et $\mathrm{al}^{13}$ compared the analgesic effect of intrapleural analgesia and epidural analgesia after VATS, and found that the median time interval between the first and second injection of $0.375 \%$ intrapleural ropivacaine for pain control was $180 \mathrm{~min}$, with an increase in the NRS score over the ensuing $4 \mathrm{~h}$. The currently approved measures that can prolong the analgesic time of local anesthetics include the addition of local anesthetic adjuvants such as dexmedetomidine and dexamethasone. ${ }^{14}$ Since there was no standard concentration and dosing of local anesthetic adjuvants used in intrapleural blockades, and there is still a lack of relevant reports, the use of adjuvants needs to be cautiously approached. In addition, some studies have compared the use of $20 \mathrm{~mL}$ and $40 \mathrm{~mL}$ bupivacaine in intrapleural analgesia after VATS and found that the volume of local anesthetic had no effect on the duration of analgesia. ${ }^{15,16}$ Therefore, intermittent repeated administration is a method that can provide continuous analgesic effects. Based on the NRS score and duration of analgesia after intrapleural administration, $4 \mathrm{~h}$ was selected as the
A

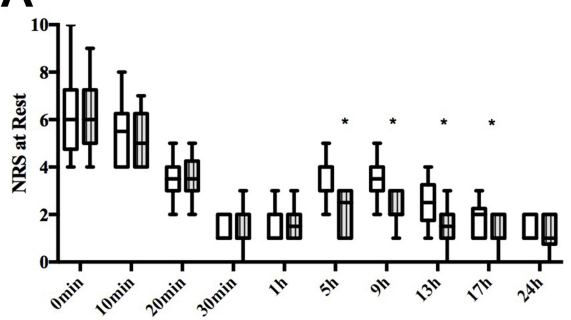

B

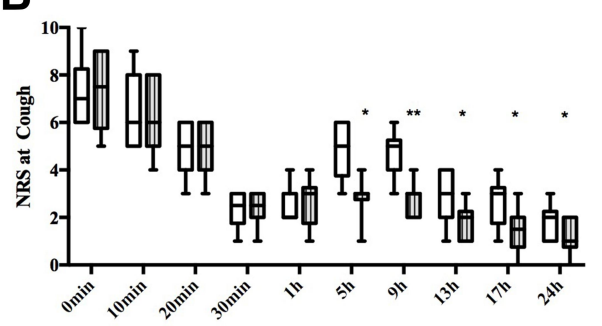

Figure 3 NRS scores at rest and coughing between two groups. (A) The NRS at rest. (B) The NRS at cough. The bars depict medians; boxes depict IQR; extended bars depict the minimal and maximum NRS values. SA group: the single administration group; RA group: the repeated administration group. $*$ Compared to SA group, $P<0.05$, $* * P<0.01$. 
appropriate time interval. Our team recently have found that in continuous paravertebral block, local anesthetic administered as a programmed intermittent bolus provided superior postoperative analgesia to continuous infusion in patients undergoing video-assisted thoracoscopic unilateral lung resection surgery. ${ }^{9}$ Besides, the benefits of programmed intermittent bolus infusion have been also observed in continuous popliteal sciatic and epidural blockade. ${ }^{17,18}$ Thus, we chose a bolus administration rather than continuous infusion.

Previous clinical studies have shown that intrapleural analgesia can reduce opioid consumption in patients after surgery. ${ }^{19,20}$ Chen et $^{6}{ }^{6}$ reported that the 24 h morphine consumption in patients after intrapleural analgesia with $0.75 \%$ ropivacaine at volumes of $20 \mathrm{~mL}$ and $15 \mathrm{~mL}$ were both significantly lower than the $10 \mathrm{~mL}$ dose. Silva et $\mathrm{al}^{8}$ compared the analgesic effects of different concentrations of intrapleural administered ropivacaine $(0.33 \%$ vs $0.5 \%$ [20 mL volumes]), after thoracic sympathectomy, and found that the higher administered concentration provided a better analgesic effect. The correlation between thoracic postoperative pain and the recovery of lung function exists only in the early postoperative period. $^{21}$ In this study, we chose ropivacaine at a concentration of $0.75 \%$ (15 $\mathrm{mL}$ doses $)$, and a total of 4 doses in the repeated administration group. In order to verify whether repeated administration can reduce the amount of analgesics used in the early postoperative period, we recorded the $24 \mathrm{~h}$ morphine consumption after surgery. Our results showed that after repeated administration, the $24 \mathrm{~h}$ morphine consumption of patients after thoracoscopic lobectomy was 9.0 $\pm 5.66 \mathrm{mg}$, which was significantly lower than that of patients who received a single intrapleural ropivacaine administration $(15.9 \pm 3.48 \mathrm{mg})$. In addition, the NRS scores during coughing in the repeated administration group from $5 \mathrm{~h}$ to $24 \mathrm{~h}$ after surgery were lower than those of the single administration group, indicating that the analgesic effect in the repeated intrapleural administration group was more durable.

Systemic toxicity of local anesthetics includes neurotoxicity and cardiovascular toxicity, which is primarily caused by excessive doses or high plasma concentrations of local anesthetics, or in patients who are sensitive to local anesthesia. This study examined plasma ropivacaine concentrations in order to confirm whether repeated administration would cause local anesthetic toxicity. We determined the plasma concentration after the first and fourth administration in the repeated administration group to determine whether an unsafe ropivacaine accumulation occurred. The highest ropivacaine concentration after single administration was $1345 \pm 364 \mathrm{ug} / \mathrm{L}$, while the highest concentration after the fourth administration was
$1864 \pm 492 \mathrm{ug} / \mathrm{L}$ in the repeated administration group. However, it was still lower than the plasma concentration of $2.2 \mathrm{mg} / \mathrm{mL}$ and $2.7 \mathrm{mg} / \mathrm{mL}$ at which concentration local anesthetic toxicity has been reported. ${ }^{20,21}$ In our study, there was no local anesthetic toxicity in either group, and no significant difference in hemodynamic parameters, nausea, vomiting, and/or dizziness. These results demonstrated the safety of repeated intrapleural administration of $0.75 \%$ ropivacaine $15 \mathrm{~mL}$ every $4 \mathrm{~h}$ for 4 doses.

There were limitations to our study. First, the dose of repeated administration in this study was $0.75 \%$ ropivacaine $15 \mathrm{~mL}$, and in order to reduce the accumulation of drugs and the possibility of local anesthetics toxicity, the optimal concentration and dosage in repeated administration of ropivacaine should be explored in subsequent studies. Second, we only determined the plasma concentration after the first and fourth administration in the repeated administration group, therefore, the pharmacokinetic data of the two groups was incomplete. Third, the study was not double-blinded (although those researchers who participated in scoring the pain did not know the grouping).

In summary, compared with a single intrapleural administration, the repeated intrapleural administration with $0.75 \%$ ropivacaine $15 \mathrm{~mL}$ every $4 \mathrm{~h}$ for 4 doses after thoracoscopic lobectomy may provide patients with more durable and effective postoperative analgesia, with a possible safe range of plasma ropivacaine concentrations. Further studies need to be undertaken to confirm our findings.

\section{Data Sharing Statement}

The corresponding author (Yiquan Wu, wuyiquanspring@126.com) will be ready to send all related data for any authority on request by an email message. The data will be available this way for up to 6 months after the paper is published.

\section{Ethical Statement}

The authors declare that all patients gave written informed consent before initiation of the study protocol and was conducted in accordance with the Declaration of Helsinki. The study was approved by the Ethics Committee of the First Affiliated Hospital of Wenzhou Medical University (No. ChiCTR-IOR-17010560).

\section{Author Contributions}

All authors contributed to data analysis, drafting or revising the article, have agreed on the journal to which the article will 
be submitted, gave final approval of the version to be published, and agree to be accountable for all aspects of the work.

\section{Funding}

This work is supported by Wenzhou Science and Technology Bureau (Y20180592, Wenzhou, China).

\section{Disclosure}

The authors report no conflicts of interest in this work.

\section{References}

1. Wildgaard K, Petersen RH, Hansen HJ, Moller-Sorensen H, Ringsted TK, Kehlet $H$. Multimodal analgesic treatment in video-assisted thoracic surgery lobectomy using an intraoperative intercostal catheter. Eur J Cardiothorac Surg. 2012;41(5):1072-1077. doi:10.1093/ejcts/ezr151

2. Bolotin G, Lazarovici H, Uretzky G, Zlotnick AY, Tamir A, Saute M. The efficacy of intraoperative internal intercostal nerve block during video-assisted thoracic surgery on postoperative pain. Ann Thorac Surg. 2000;70(6):1872-1875. doi:10.1016/S0003-4975(00)01757-4

3. Hill SE, Keller RA, Stafford-Smith M, et al. Efficacy of single-dose, multilevel paravertebral nerve blockade for analgesia after thoracoscopic procedures. Anesthesiology. 2006;104(5):1047-1053. doi:10.1097/00000542-200605000-00022

4. Forcella D, Pompeo E, Coniglione F, Gatti A, Mineo TC. A new technique for continuous intercostal-intrapleural analgesia in videothoracoscopic surgery. J Thorac Cardiovasc Surg. 2009;137(1): e48-49. doi:10.1016/j.jtcvs.2008.03.062

5. Demmy TL, Nwogu C, Solan P, Yendamuri S, Wilding G, DeLeon O. Chest tube-delivered bupivacaine improves pain and decreases opioid use after thoracoscopy. Ann Thorac Surg. 2009;87(4):1040-1046; discussion 1046-1047. doi:10.1016/j.athoracsur.2008.12.099

6. Chen S, Zhu X, Huang L, et al. Optimal dose of ropivacaine for relieving cough-pain after video-assisted thoracoscopic lobectomy by single intrapleural injection: a randomized, double-blind, controlled study. Int J Surg. 2019;69:132-138. doi:10.1016/j.ijsu.2019.05.013

7. Tetik O, Islamoglu F, Ayan E, Duran M, Buket S, Cekirdekci A. Intermittent infusion of $0.25 \%$ bupivacaine through an intrapleural catheter for post-thoracotomy pain relief. Ann Thorac Surg. 2004;77 (1):284-288. doi:10.1016/S0003-4975(03)01338-9

8. Silva PG, Cataneo DC, Leite F, Hasimoto EN, Barros GA. Intrapleural analgesia after endoscopic thoracic sympathectomy. Acta Cir Bras. 2011;26(6):508-513. doi:10.1590/S0102-86502011000600017

9. Chen L, Wu Y, Cai Y, et al. Comparison of programmed intermittent bolus infusion and continuous infusion for postoperative patient-controlled analgesia with thoracic paravertebral block catheter: a randomized, double-blind, controlled trial. Reg Anesth Pain Med. 2019;44(2):240-245. doi:10.1136/rapm-2018-000031

Journal of Pain Research

\section{Publish your work in this journal}

The Journal of Pain Research is an international, peer reviewed, open access, online journal that welcomes laboratory and clinical findings in the fields of pain research and the prevention and management of pain. Original research, reviews, symposium reports, hypothesis formation and commentaries are all considered for publication. The manuscript

Submit your manuscript here: https://www.dovepress.com/journal-of-pain-research-journal
10. Durrani Z, Winnie AP, Ikuta P. Interpleural catheter analgesia for pancreatic pain. Anesth Analg. 1988;67(5):479-481. doi:10.1213/ 00000539-198805000-00013

11. McKenzie AG, Mathe S. Interpleural local anaesthesia: anatomical basis for mechanism of action. Br J Anaesth. 1996;76(2):297-299. doi:10.1093/bja/76.2.297

12. Perttunen K, Nilsson E, Kalso E. I.v. diclofenac and ketorolac for pain after thoracoscopic surgery. Br J Anaesth. 1999;82(2):221-227. doi: $10.1093 / \mathrm{bja} / 82.2 .221$

13. Ishikawa $\mathrm{Y}$, Maehara $\mathrm{T}$, Nishii $\mathrm{T}$, et al. Intrapleural analgesia using ropivacaine for postoperative pain relief after minimally invasive thoracoscopic surgery. Ann Thorac Cardiovasc Surg. 2012;18 (5):429-433. doi:10.5761/atcs.oa.11.01854

14. Zhang P, Liu S, Zhu J, Rao Z, Liu C. Dexamethasone and dexmedetomidine as adjuvants to local anesthetic mixture in intercostal nerve block for thoracoscopic pneumonectomy: a prospective randomized study. Reg Anesth Pain Med. 2019;44(10):917-922. doi:10.1136/ rapm-2018-100221

15. Stromskag KE, Minor BG, Lindeberg A. Comparison of 40 milliliters of $0.25 \%$ intrapleural bupivacaine with epinephrine with 20 milliliters of $0.5 \%$ intrapleural bupivacaine with epinephrine after cholecystectomy. Anesth Analg. 1991;73(4):397-400.

16. Seltzer JL, Larijani GE, Goldberg ME, Marr AT. Intrapleural bupivacaine-a kinetic and dynamic evaluation. Anesthesiology. 1987;67 (5):798-800. doi:10.1097/00000542-198711000-00029

17. Leo S, Ocampo CE, Lim Y, Sia AT. A randomized comparison of automated intermittent mandatory boluses with a basal infusion in combination with patient-controlled epidural analgesia for labor and delivery. Int J Obstet Anesth. 2010;19(4):357-364. doi:10.1016/j. ijoa.2010.07.006

18. Taboada M, Rodriguez J, Bermudez M, et al. Comparison of continuous infusion versus automated bolus for postoperative patient-controlled analgesia with popliteal sciatic nerve catheters. Anesthesiology. 2009;110(1):150-154. doi:10.1097/ ALN.0b013e318191693a

19. Assalia A, Kopelman D, Markovits R, Hashmonai M. Intrapleural analgesia following thoracoscopic sympathectomy for palmar hyperhidrosis: a prospective, randomized trial. Surg Endosc. 2003;17 (6):921-922. doi:10.1007/s00464-002-8733-x

20. Lieou FJ, Lee SC, Ho ST, Wang JJ. Interpleural bupivacaine for pain relief after transthoracic endoscopic sympathectomy for primary hyperhidrosis. Acta Anaesthesiol Sin. 1996;34(1):21-25.

21. Nagahiro I, Andou A, Aoe M, Sano Y, Date H, Shimizu N. Pulmonary function, postoperative pain, and serum cytokine level after lobectomy: a comparison of VATS and conventional procedure. Ann Thorac Surg. 2001;72(2):362-365. doi:10.1016/ S0003-4975(01)02804-1 management system is completely online and includes a very quick and fair peer-review system, which is all easy to use. Visit http:// www.dovepress.com/testimonials.php to read real quotes from published authors. 